$41(3) \mid 2012$

Recomposiciones territoriales de las periferias de las metrópolis andinas

\title{
Ruralidad metropolitana. Entre la tradición rural y el «brillo» urbano. Una interpretación
}

Ruralité métropolitaine. Entre la tradition rurale et "l'éclat » de la ville. Une interprétation

Metropolitan rurality: between rural tradition and urban «brightness» - An interpretation

Luis Carlos Agudelo Patiño

\section{OpenEdition}

Journals

Edición electrónica

URL: http://journals.openedition.org/bifea/432

DOI: $10.4000 /$ bifea.432

ISSN: 2076-5827

Editor

Institut Français d'Études Andines

Edición impresa

Fecha de publicación: 31 diciembre 2012

Paginación: 555-571

ISSN: 0303-7495

Referencia electrónica

Luis Carlos Agudelo Patiño, «Ruralidad metropolitana. Entre la tradición rural y el «brillo» urbano. Una interpretación », Bulletin de l'Institut français d'études andines [En línea], 41 (3) | 2012, Publicado el 01 agosto 2013, consultado el 05 noviembre 2020. URL : http://journals.openedition.org/bifea/432 ; DOI : https://doi.org/10.4000/bifea.432 


\title{
Ruralidad metropolitana. Entre la tradición rural y el «brillo» urbano. Una interpretación
}

\author{
Luis Carlos Agudelo Patiño*
}

\begin{abstract}
Resumen
El trabajo examina, desde el punto de vista territorial, la condición actual de los espacios rurales metropolitanos, a partir de los paisajes y de su evolución reciente en el valle geográfico del río Aburrá que comprende el área metropolitana de Medellín. También se hace uso de narrativas literarias y de la música popular campesina y su tránsito a la tradición urbana. La ruralidad metropolitana se caracteriza por expresiones sociales y características del medio. En general el trabajo se orienta a producir una interpretación de las condiciones y dinámicas de transformación de la ruralidad metropolitana del valle de Aburrá, como base para plantear y debatir esta categoría analítica.
\end{abstract}

Palabras clave: ruralidad, periferia urbana, paisaje, campesinos metropolitanos

\section{Ruralité métropolitaine. Entre la tradition rurale et « l'éclat » de la ville. Une interprétation}

\section{Résumé}

Ce travail examine à partir d'une approche territoriale la situation actuelle des espaces ruraux métropolitains et met l'accent sur les paysages et leurs évolutions dans la vallée du río Aburrá, qui

* Doctor en urbanismo de la Universidad Politécnica de Valencia. Profesor Asociado, Universidad Nacional de Colombia, sede Medellin, Escuela de Planeación Urbano-Regional. E-mail: Icagudel@ unal.edu.co 
englobe l'aire métropolitaine de Medellin. II recourt également à l'analyse de textes littéraires et de chansons populaires paysannes qui relatent la transition vers la culture urbaine. L'article décrit les expressions sociales des dynamiques des espaces ruraux et les caractéristiques du milieu physique, entendues comme co-productrices des territoires actuels. Le paysage est ainsi le reflet de cette interaction, qui est à l'origine du phénomène dénommé ici de «ruralité métropolitaine». De manière générale, ce travail vise à produire une interprétation des conditions et dynamiques de transformation de la ruralité métropolitaine dans la vallée du río Aburrá, pour poser et discuter cette catégorie analytique.

Mots clés : ruralité, périphérie urbaine, paysage, paysans métropolitains

\title{
Metropolitan rurality: between rural tradition and urban «brightness» - An interpretation
}

\begin{abstract}
From a territorial perspective, the paper examines the current condition of metropolitan rural areas, based on the landscapes and their recent evolution in the valley of the Aburrá River which comprises the metropolitan area of Medellín. Literary narratives and folk music and its transit to the urban tradition are also employed in this study. Metropolitan rurality is characterized by social expressions and features from the physical environment. Overall the paper is oriented to produce an interpretation about the conditions and transformational dynamics of the metropolitan rurality within the Aburrá valley as the basis to define and debate this analytic category.
\end{abstract}

Key words: Rurality, Urban Periphery, Landscape, Metropolitan Farmers

\section{INTRODUCCIÓN}

La fuerza de la urbanización como motor del crecimiento de las ciudades, los problemas que este proceso acarrea, la magnitud de los efectos sobre el paisaje, sobre la población y sobre la economía, en últimas, el brillo urbano, a menudo oculta a la periferia urbana, al mundo rural próximo. Este hecho innegable conlleva a que los campesinos tradicionales metropolitanos tiendan a desaparecer de las agendas de desarrollo, especialmente, en entornos de gran dinámica urbana. Es así como el balance de las inversiones, las dotaciones, los proyectos de desarrollo y en general la atención de los gobiernos locales, no guarda proporción con la que se destina a sectores y poblaciones urbanas, aún se trate de las más marginadas de la ciudad.

Con el tiempo, los campesinos metropolitanos tradicionales, esa especie como de casta antigua de pobladores, esa suerte de «sociedad anacrónica», se ha visto mezclada con habitantes urbanos que retornan a sus raíces 1 y/o que quieren

1 Una versión preliminar de este trabajo fue el resultado parcial del trabajo de año sabático del autor en 2010. 
escapar de la ciudad. Sus usos, costumbres, prácticas de apropiación del espacio, instalan en los antiguos espacios rurales agrarios actividades típicamente urbanas que atraen hacia estos lugares, especialmente los fines de semana y periodos de vacaciones, a grandes contingentes de población urbana: turistas, paseantes... Algunos de ellos no querrán irse del campo y terminarán por traer el brillo urbano a la tradición rural que se resiste a desaparecer por completo. Para ese momento, el campesino metropolitano ya no es el habitante tradicional.

El texto se ha organizado en dos partes, que siguen a esta introducción. La primera parte recoge una descripción de la ruralidad metropolitana, cuyos rasgos han sido definidos entre otros por Monclús (1998); Aguilera (1991), Estebanez (1988), desde el punto de vista de los procesos de transformación del territorio que producen paisajes y configuraciones típicas de la ruralidad próxima a un espacio urbano de cierta magnitud. Los referentes empíricos provienen del valle geográfico del río Aburrá, que alberga a un conglomerado urbano de 3 millones de habitantes, de los cuales al menos 2 millones se ubican en la ciudad de Medellín, la capital del departamento de Antioquia. Administrativamente se conforman en un Área Metropolitana de 10 municipios: Bello, Envigado, Itaguí, La Estrella, Caldas, Sabaneta, Copacabana, Girardota y Barbosa, además de Medellín. La segunda parte caracteriza propiamente a la población rural metropolitana, tanto en cuanto a sus características demográficas y rasgos culturales leídos en parte a través de narrativas literarias y musicales, así como en lo que se podría llamar el conjunto de problemas y ventajas propias de esta situación territorial de frontera metropolitana.

El trabajo no pretende proponer una nueva categoría sociológica de campesino metropolitano2 ${ }^{2}$ En cambio se avanza sobre la categoría territorial de Ruralidad metropolitana y se hace un intento explicativo de una realidad territorial compleja y dinámica, que reclama reflexiones y elaboraciones teóricas más rigurosas, las mismas que se espera provocar con este texto.

El artículo recurre a narrativas de la música y la literatura, no de forma sistemática, pero sí como ilustración de los argumentos. Conviene insistir en que no se trata de una aplicación rigurosa de la técnica narrativa como método de investigación; más bien, como se indicó, se hace una aproximación con fines meramente ilustrativos, de un aspecto crucial de la reciente memoria rural de los habitantes urbanos de nuestras ciudades latinoamericanas. Lo anterior constituye una aproximación que espera comunicar el poder explicativo de estos acercamientos a través de las narrativas, antes que agotar o aplicar rigurosamente una investigación sobre narrativas.

2 No hay que olvidar el postulado de que las nuestras son «Ciudades de Campesinos» (Roberts, 1980). 


\section{EL TERRITORIO RURAL METROPOLITANO}

Está bastante extendido el debate en torno a la vigencia de la separación entre lo urbano y lo rural. El resultado parece favorecer en términos teóricos a la perspectiva europea expuesta por Baigorri (1995), que propone la disolución del objeto de estudio de la sociología rural clásica y la emergencia de una nueva sociología de los procesos de urbanización. No obstante, esta perspectiva teórica admite discusiones importantes para el caso de América Latina, dado que persiste una ruralidad en buena medida excluida de los procesos de urbanización cultural, o lo que es lo mismo, aislada en territorios rurales tradicionales que aún permanecen fuera del mercado global. Más aún, persisten esos elementos agrarios tradicionales en entornos metropolitanos.

Para describir la fenomenología que envuelve la dinámica de los procesos de cambio en el mundo rural latinoamericano, se ha acudido al expediente de la nueva ruralidad, cuyo escaso y volátil cuerpo teórico no alcanza a dar cuenta de una dinámica compleja y diferenciada entre regiones y naciones, abonada por la multiplicidad de microgeografías subnacionales. Adonde sí resulta muy eficaz el ideario de la nueva ruralidad es en espacios rurales integrados o bien en el mercado de excedentes agroindustriales de actividades lícitas (otra cosa ocurre con la agroindustria de cultivos de uso ilegal) y en espacios rurales próximos a grandes centros metropolitanos, ya plenamente integrados a procesos de urbanización, sin rasgos de ruralidad tradicional. Estos últimos son escazos en la geografía colombiana. Corresponden básicamente a las ciudades capitales. Veamos: de acuerdo con el Censo de 2005 (DANE, 2005), 7 municipios reportaron población mayor de 500000 habitantes. 325 municipios, cerca del $30 \%$ del total nacional, presentaron población en promedio de 14000 habitantes. Los 7 municipios mayores, con procesos fuertes de urbanización, corresponden en efecto a ciudades capitales.

Una interesante crítica al concepto de nueva ruralidad, se puede leer en Arias (2006):

«la noción de nueva ruralidad surge como un intento de enmarcar en un solo concepto, los complejos cambios experimentados como resultado de la aplicación de reformas neoliberales... Aunque estos intentos de conceptualizar la nueva ruralidad son necesarios y útiles, no escapan a la dificultad tradicional de definir lo rural, lo que hace que muchos de los esfuerzos realizados, deriven en generalizaciones...».

Lo anterior propone la necesidad de diferenciar ámbitos de ruralidad al momento de proponer categorías teóricas, criterios de análisis, proyectos de desarrollo y acciones de planificación territorial sobre el mundo rural.

Este trabajo examina concretamente uno de esos posibles ámbitos de diferenciación de ruralidad, la ruralidad metropolitana. Parte de considerar que la influencia metropolitana es suficiente para generar unos paisajes típicos de frontera urbano-rural o un espacio rural urbanizado. Del mismo modo y en consecuencia, esa misma influencia debe determinar transformaciones sociales 
y culturales producto de la convivencia entre la población rural tradicional (influenciada por el vecindario urbano) y la población urbana (con raíces rurales recientes) que de forma creciente ocupa y habita espacios rurales próximos a los centros metropolitanos. Se consideran desde luego tanto las transformaciones (la urbanización) de la sociedad rural tradicional, como la emergencia de un conjunto de valores ambientales y psicológicos en el seno de la sociedad urbana metropolitana, que dictan una revaloración de los modos de vida, los paisajes y en general, de la ruralidad en su versión más clásica; la ruralidad agraria.

En principio, el efecto territorial, es decir, el espacio que organizan los procesos de urbanización en su entorno, la magnitud, el tamaño del área de influencia metropolitana en el suelo rural, estaría ligado, de acuerdo con Estébanez (1988), a dos principios generales de cambio espacial:

- Principio de Gradiente, según el cual el grado de influencia urbana en el entorno rural decrece con la mayor distancia a la ciudad más próxima y crece con el tamaño de la ciudad.

Este gradiente es afectado por el desarrollo vial y los medios de transporte que relativizan las distancias al reducir los tiempos para cubrirlas. La potencia del centro urbano metropolitano determina la distancia a la que se forman las manchas rurales metropolitanas o espacios rurales urbanizados.

- Principio de diferenciación. Propone que el grado de especialización y diferenciación espacial (subáreas) del suelo rural, decrece con la mayor distancia a la ciudad más cercana y crece con el mayor tamaño de la ciudad. Eso significa que espacios rurales próximos a grandes ciudades tienden a la heterogeneidad, la misma que crece cuanto más cerca se está de una ciudad grande.

Por ejemplo, un espacio rural urbanizado puede presentar simultáneamente usos agrícolas, pecuarios, industriales, comerciales, recreativos, equipamientos diversos, residenciales, forestales, de protección ecológica; todos imbricados en una matriz compleja que, a determinada escala, solo permite apreciar la mezcla de usos. En contraste, en zonas rurales más profundas, a distancias considerables de los centros metropolitanos, el paisaje rural se simplifica al punto de que queda esencialmente definido por usos agrarios, pecuarios y zonas de conservación. El altiplano oriental de Antioquia, en el cual se ubica el aeropuerto internacional que sirve a Medellín, ejemplifica bien un entorno heterógeneo en usos, cercano al centro metropolitano.

Las transformaciones espaciales que operan en el medio rural, la cercanía y el tamaño de la ciudad, tienen a su vez diferentes formas o reflejos en elementos propios del paisaje; en esencia se trata de una mayor diversidad de usos a medida que se avanza hacia el núcleo urbano consolidado, en especial en los ejes viales. Esa diversidad rompe la analogía histórica que considera sinónimos rural y agrario y genera espacios rurales caracterizados por la presencia de usos típicamente urbanos y de infraestructuras que demanda el funcionamiento urbano. De inmediato opera otra transformación territorial definitiva, esta vez en el orden 
económico: el suelo, que en el mundo rural agrario se transaba según su valor de uso (fertilidad, productividad), cobra valor de cambio ligado a la localización, la cercanía a equipamientos... en general, ligado estrechamente a la dotación urbanística. Por ejemplo, la región que comprende el Altiplano oriental o Valle de San Nicolás ha visto, en un periodo menor a 30 años, precios del suelo medido en pesos por metro cuadrado en bruto, pasar de cerca de 5 mil ( 2 US\$) a 70 mil $(35 \cup S \$$ )3. La tierra que se vendía en hectáreas tiempo atrás, se negocia ahora en metros cuadrados.

En este punto conviene volver sobre la diferenciación entre esos dos términos comúnmente, y hasta la revolución industrial, correctamente utilizados como sinónimos en cualquier lugar del planeta: rural y agrario. El término agrario, del latín «ager» significa campo, tierra cultivada, lo que en cualquier caso alude a la utilización del suelo por parte del sector primario de la economía. Mientras que el término rural, proviene del latín «rus» que significa igualmente campo, pero en contraposición al término «urbs» que significa ciudad, urbe (Aguilera et al., 1991). Se trata de una definición por negación de lo rural: lo que no es ciudad.

La coincidencia entre estos dos conceptos se percibe en los paisajes rurales dedicados a la agricultura. En oposición a lo anterior, lo que ha generado la demanda de suelo rural para usos no agrarios, es un conjunto de paisajes rurales agroindustriales, industriales rurales, de segundas residencias, comercio e infraestructuras varias (embalses, centrales de energía, rellenos sanitarios, aeropuertos, etc.); de manera que en la actualidad, un rasgo distintivo de la separación urbano rural es que lo rural no es necesariamente agrario. Pero, desde el punto de vista de los elementos que integran los paisajes rurales, lo rural como matriz esencialmente verde, cultivada, con múltiples parches y corredores de actividad, tampoco coincide con los rasgos de un paisaje urbano. La ruralidad metropolitana se refiere a espacios urbanizados (transformados por los procesos de urbanización), pero que conservan en sus paisajes característicos, importantes elementos rurales y agrarios.

Se puede verificar la existencia de un conjunto de efectos territoriales de los procesos de urbanización, cuya magnitud, intensidad y recurrencia espacial, configuran lo que se puede llamar paisajes rurales metropolitanos. Veamos:

Cuando ocurre una implantación urbana en el territorio, es decir, cuando se instalan usos típicamente urbanos en el suelo suburbano, periurbano o rural, es porque una serie de requisitos mínimos se han cumplido. Estos pueden resumirse en dos grupos: accesibilidad y servicios públicos. Ambos servicios se instalan como resultado de planeamiento o por el solo desarrollo de dinámicas de expansión de la urbanización ajenas a los planes formales. Por ejemplo, uno de los principios del Plan de Ordenamiento Territorial de Medellín4, es el crecimiento hacia adentro.

3 Los valores fueron obtenidos en entrevista telefónica con personal de La Lonja de Propiedad Raíz de Medellín y corresponden a medias de los precios en la zona en ambos momentos.

4 Acuerdo 046 de 2006, Municipio de Medellín. 
En contra de este principio, este municipio programó más suelo de expansión urbana que ningún otro en el área metropolitana, si se consideran los primeros planes de ordenamiento aprobados (Agudelo, 2002).

Lo que viene tras la primera implantación de usos urbanos, especialmente cuando esta tiene lugar en suelo no urbano, es una serie de intervenciones iguales o complementarias: viviendas y servicios, comercio, ocio, etc. De modo que el impacto ambiental del proyecto pionero, tasado en efectos sobre el suelo, el aire, la vegetación, etc., es mínimo si se compara con el impacto territorial que desata la economía de localización del nuevo uso urbano. Es en este momento que se inicia la transformación del valor de uso por valor de cambio, descrita atrás.

Lo que sigue es más de lo mismo: un proceso de urbanización del campo que se intensifica cuanto mejor se van resolviendo los requisitos básicos, accesibilidad y servicios públicos. ¿Hasta qué punto se intensifica? Lo deseable para los habitantes de estos espacios, que combinan las calidades ambientales de la vida rural con las comodidades de la vida urbana, sería mantener exactamente ese balance. A la larga, difícilmente lo consiguen, ya que el mayor precio del suelo presiona al alza a la densidad, de modo que solo son viables proyectos de urbanización y/o iniciativas individuales de urbanización del suelo rural, cuando el precio del suelo en bruto es demasiado alto. Como los precios ya se han elevado lo suficiente, la estrategia es comprar poco suelo, es decir, aumentar la densidad. Es una condición de mercado ineludible. Procesos como estos están teniendo lugar en el corregimiento de Santa Elena — el más tradicional por la floricultura y las silletas, emblemáticas de Medellín-, con mayor intensidad en las veredas aledañas a los ejes viales, pero con tendencia a su expansión en todo el corregimiento. Procesos similares ocurren en otros corregimientos de Medellín como San Cristobal, ligado al proyecto vial Aburrá-Río Cauca. También ocurre en el norte, en el entorno vial de la autopista y cerca a las cabeceras de Girardota, Copacabana y Barbosa y en el sur, con diferente intensidad, en prácticamente todos los municipios.

Paradójicamente la especulación aleja compradores y de alguna manera «selecciona» a los habitantes de los espacios periurbanos y rururbanos. Pero la fuerza del mercado y un débil control estatal se combinan para desatar ciudadelas de viviendas no adosadas, que comienzan a demandar soluciones de saneamiento básico y equipamiento verdaderamente urbanas. En materia de servicios públicos, el pozo séptico debe sustituirse por redes de alcantarillado, colapsa el acueducto veredal y se impone la conexión a redes más extensas.

Lo mismo ocurre con el gas, la electrificación, la telefonía, la seguridad... El sueño de la vida en el campo se ha convertido en la pesadilla del suburbio (Agudelo, 2002). Esta tendencia se registra en muchas localidades del valle de Aburrá, en el oriente cercano y más recientemente, en la cuenca de la Iguaná y en el occidente cercano. Así lo revelan los paisajes suburbiales que caracterizan esta periferia metropolitana de Medellín.

En consecuencia, el espacio rural metropolitano se caracteriza por paisajes rurales urbanizados, que no son otra cosa que paisajes agrarios transformados en su estructura, en su función y por tanto en su apariencia rural-agraria tradicional. 
No hay duda de que la apariencia es un rasgo distintivo de la ruralidad. En vista de ello, conviene acudir a la noción de paisaje agrario, a fin de ir construyendo por agregación de rasgos nuevos, una noción de proceso de paisaje rural metropolitano, útil a nuestro propósito analítico.

Un paisaje agrario es el resultado de la acción conjunta de componentes físicos, biológicos y culturales sobre un espacio económico no urbano de la superficie terrestre. En cuanto a la estructura agraria, Bonnamour (1970), citado por Aguilera (1991) señala que esta «designa tanto las formas de propiedad y explotación de la tierra agrícola, como los paisajes formados por el parcelario de los campos y la distribución del hábitat rural. Por tanto, las organizaciones económicas y sociales observadas en una región se reflejan más o menos en el paisaje agrario que expresa, por otra parte, la influencia de las técnicas agrícolas y de las técnicas de organización del espacio del grupo considerado». Examinemos uno a uno los cambios en estructura, función y apariencia del paisaje agrario tradicional.

La estructura de un paisaje agrario tiene dos componentes esenciales: los elementos y los factores (Aguilera et al., 1991). Los elementos se constituyen por todos los aspectos visibles del paisaje, de los cuales se puede apreciar una localización, un patrón de distribución y una forma y/o magnitud específicas: las parcelas, los cultivos, las viviendas, los establos, los graneros, los cercados, las vallas, los caminos, la topografía... En segundo lugar, los factores que ayudan a explicar y dan sentido al paisaje, sin que aparezcan reflejados como elementos.

Cuando un paisaje rural agrario tradicional se transforma, los primeros elementos que cambian —al menos lo más conspicuos_ son la vivienda y los cultivos. Las tipologías de vivienda rural se diversifican para incorporar viviendas suntuarias, bien nuevas o bien producto de transformaciones de las antiguas viviendas rurales, al tiempo que aparecen más viviendas rurales modestas, que son ocupadas paulatinamente por campesinos asalariados vinculados a las nuevas labores rurales: servicios de vigilancia, jardinería, comercio, entre otras. La zona norte del área metropolitana, en el entorno de Copacabana y Girardota ilustra bien este tipo de proceso. Allí, la fragmentación predial, la sustitución de población originaria, la desaparición de la agricultura, la generalización de usos recreativos del agua, la hiperdensificación vial y los cerramientos de predios, son rasgos característicos de la urbanización del suelo rural ya consolidada (AMVA-UN, 2011).

Los cultivos y los pastos manejados para ganadería, que dominaban por lo común la matriz del paisaje rural tradicional, con un predominio claro de los segundos5 (Uribe, 1885), dan paso a una mezcla en la que los pastos manejados para recreación, ocupan espacio en la matriz tradicional modificada. Ambos cambios implican una mayor densidad de vivienda y desatan una gran variedad de usos nuevos que contribuyen a la reconfiguración de la estructura del paisaje

5 Los nombres originales de los municipios de Bello, Girardota, y Barbosa en su orden eran Hato Viejo, Hato Grande y Hatillo, lo cual revela la vocación ganadera del territorio metropolitano de Medellín, especialmente en las vegas planas y en las colinas del norte del valle geográfico. 
rural agrario. Estos nuevos usos agregan nuevos elementos: establecimientos de comercio del ocio tipo restaurantes, estaderos, centros comerciales, estaciones de servicio, centros recreativos, nuevas vías vehiculares... en fin, una serie de edificaciones cuyos usuarios son principalmente la nueva población de campesinos que no labran tierra ni crían animales. A la mayor densidad de viviendas se suma un incremento de la densidad vial y una explosión de diferentes usos en nodos localizados a lo largo de los ejes viales principales. En este momento, el arreglo del paisaje rural agrario tradicional ha cambiado a un paisaje rural metropolitano (figs. 1 y 2).

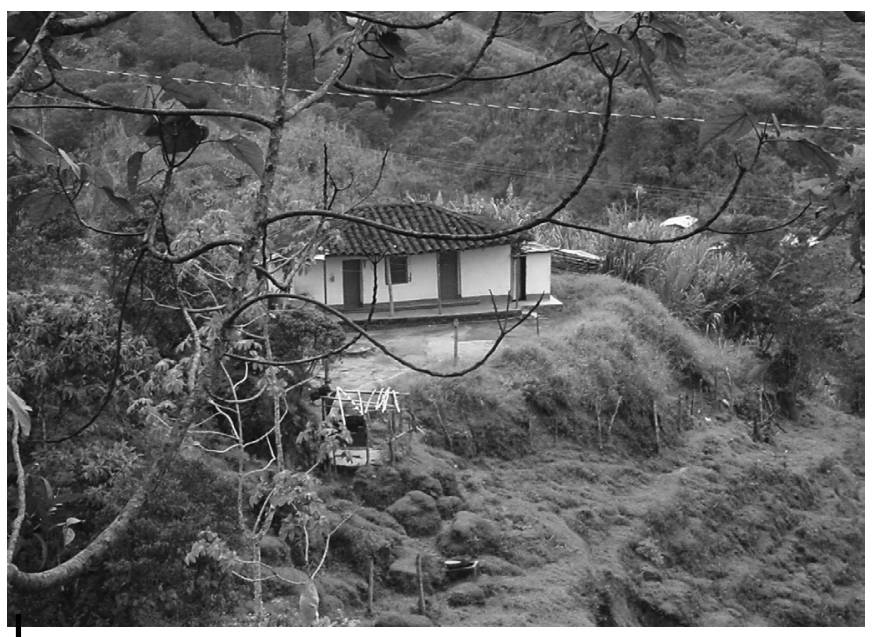

Figura 1 - Paisaje rural agrario tradicional y vivienda típica

Municipio de Granada (Antioquia)

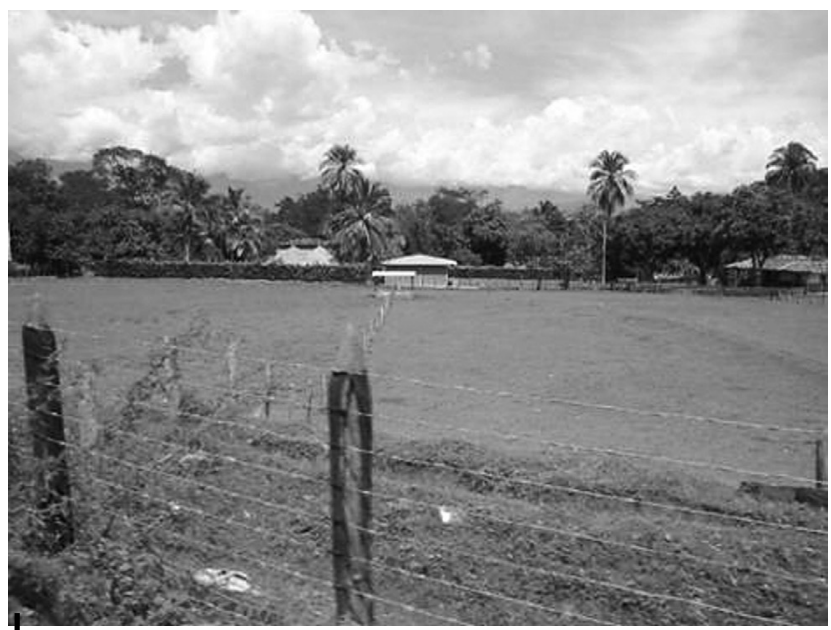

Figura 2 - Paisaje rural agrario urbanizado. Vivienda típica

Municipio de Santafe de Antioquia 
Una confluencia de factores ha favorecido esta transformación de un paisaje rural agrario tradicional en un paisaje rural metropolitano. En primer lugar, la cercanía del área urbana consolidada en expansión garantiza la comunicación con el centro de ciudad y sus equipamientos y servicios. Esta misma cercanía se incrementa con el desarrollo vial propio de los centros metropolitanos, que requiere la comunicación rápida entre grandes centros urbanos nacionales, puertos y aeropuertos.

Como consecuencia, se produce el fenómeno ya descrito: el suelo gana valor de cambio y la renta rural agraria no puede competir con la renta urbana del suelo. Este proceso se ha consolidado plenamente en Llano Grande, Municipio de Rionegro y avanza en sectores de los corregimientos de Medellín, Santa Elena y San Cristobal. En estas condiciones, la agricultura tradicional se deprime y la fragmentación inicial de antiguos fundos rurales se consolida.

Al principio, el agricultor o ganadero vende una parte de su predio para una vivienda urbana. Posteriormente y tras reinvertir sin demasiado éxito en la empresa agraria de su reducido predio, termina por vender hasta una casa tradicional para usos urbanos. En el paisaje rural metropolitano, estas viviendas reformadas aparecen adecuadas al nuevo uso urbano: el patio da paso al parqueadero y la piscina por lo general se instala cerca de la casa, se cambian los colores, el techo, algunos materiales; el predio adquiere finalmente una nueva función, la casa lo denota. No se trata ya de una unidad de vivienda con adecuaciones (sobre construcciones) de apoyo a la actividad agraria en el predio, sino de una vivienda para fines recreativos (fig. 3).

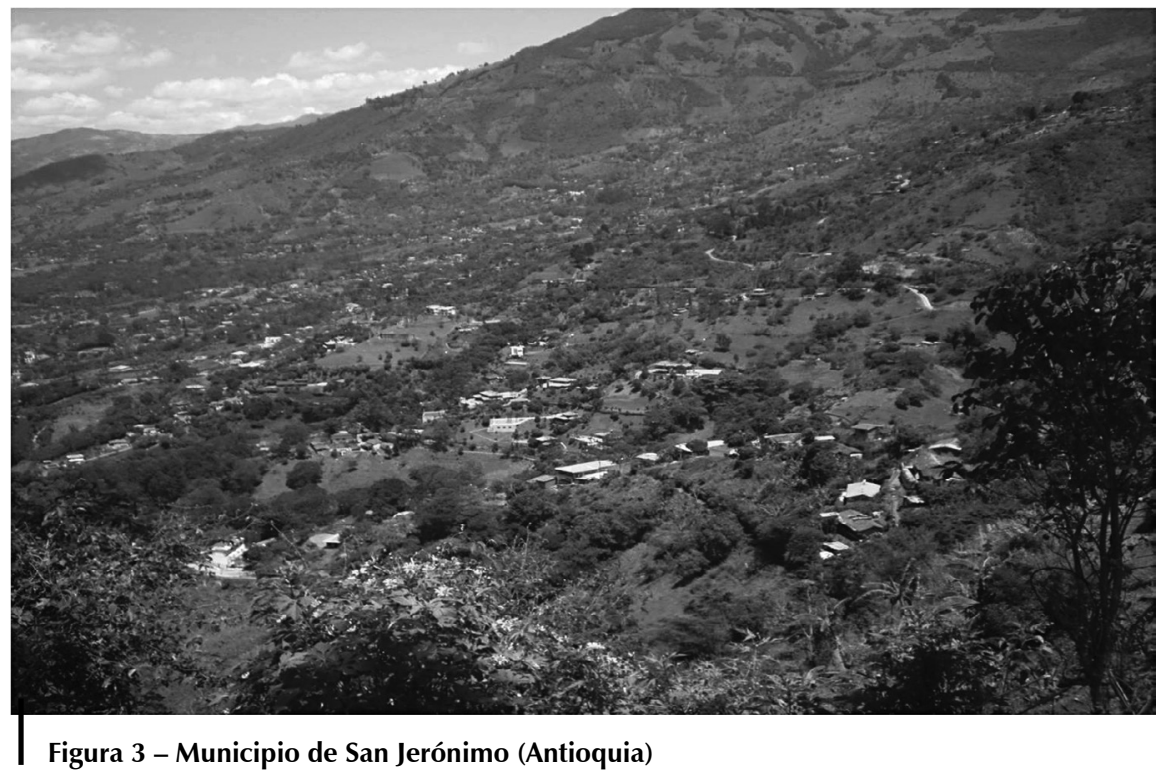

Aspectos de paisajes típicos de ruralidad metropolitana 
En cuanto a la apariencia, en el paisaje rural agrario, los elementos recurrentes en el espacio proyectan la imagen de una estructura simple pero diversa en formas y colores, además de muy dinámica, en especial en paisajes rurales agrarios dominados por cultivos de ciclo corto. En contraste, los paisajes rurales metropolitanos se caracterizan, tal como lo apuntó Estébanez (1998), por una gran diversidad de usos y una mayor densidad general en materia vial, demográfica, de viviendas y de actividades (figs. 1 y 2). Aunque se mantiene una matriz general «verde» en la que predominan los pastos, y no la ganadería, la estructura, una disposición de los elementos y la función del paisaje rural agrario ha cambiado para siempre.

\section{CAMPESINOS METROPOLITANOS}

En el diccionario de la Real Academia de la Lengua Española, se extraen al menos cuatro significados de la palabra campesino:

Adj. Perteneciente o relativa al campo. 2. Adj. Propio de él. 3. Adj. Dicho de una persona: Que vive y trabaja de ordinario en el campo. U. t.c.s 4. Dj. Adj. Silvestre, espontanea, inculta (Real Academia Española, 2011).

Nótese la referencia específica al lugar de habitación y en cambio la ausencia de invocaciones al trabajo agrario en estas definiciones, excepto tal vez, en la cuarta definición, si se acepta como inculto el trabajo en el sector primario de la economía.

Wolf (1966: 3-4), citado por Skerritt (1998), propuso hace casi medio siglo, una definición de campesino:

«cultivadores rurales cuyos excedentes se transfieren al grupo dominante de los gobernantes, quienes emplean sus excedentes para asegurar su propio nivel de vida y para distribuir el restante a grupos de la sociedad no rurales, que requieren de alimentos a cambio de sus bienes y servicios».

En la definición de Wolf se destaca la connotación de cultivador para el campesino y se propone una estructura de definición que presenta al campesino como subordinado en un esquema de explotación por agentes externos. Es tentadora la metáfora con comerciantes e intermediarios de alimentos en grandes centros urbanos, que actuarían hoy como grupo dominante.

En un trabajo clásico Chayanov (1985), definió al campesino ruso de entonces, desde la óptica de la familia campesina:

«la familia campesina no contrata fuerza de trabajo exterior, tiene una cierta extensión de tierra disponible, posee sus propios medios de producción y eventualmente se ve obligada a emplear parte de su fuerza de trabajo en oficios rurales no agrícolas»».

Parafraseando a Chayanov, la familia campesina en entornos metropolitanos no contrata fuerza de trabajo, sino excepcionalmente, carece de extensiones propias 
de tierra que hagan viable la actividad de subsistencia, carece de medios propios de producción, pero de forma creciente y en ocasiones, dedica su fuerza de trabajo a labores rurales no agrícolas, relacionadas con la dinámica que impone la urbanización del suelo rural.

En el ámbito local de Medellín y su área metropolitana, las visiones sobre el mundo rural han cambiado dramáticamente en el último siglo. Básicamente pasaron de una interdependencia reconocida y vivida entre los campesinos y los habitantes de La Villa, como se llamaba entonces a la ciudad, a una invisibilizacion casi completa de los habitantes y en general del mundo rural próximo, que lo deja en un sitio anónimo en los referentes modernos de ciudad metropolitana; pasando por una visión de lo rural que enfatizaba un carácter peyorativo de atraso y pobreza y, en general, una visión que resaltaba al mundo rural como el revés de la urbe moderna. Todo lo anterior no obstante se reconoce un reciente ancestro campesino, por prácticamente la mayoría de los habitantes de la ciudad metropolitana que alberga hoy a más de tres millones de personas. Las nuestras haciendo referencia a las ciudades latinoamericanas son ciudades de campesinos, afirmó Roberts (1980).

Camilo Botero Guerra, un escritor local de las primeras décadas del siglo XX, escribió un cuento revelador de la visión de los campesinos de la época, de la Villa de Medellín, de la ciudad en plena emergencia:

«me dio la corazonada de que le han llenao la cabeza de cuentos de la villa y usted se quedó encandelillada con los brillos del oropel; porque todo eso es oropel» (Botero, 1997).

Le planteaba José a su novia Rosalía, ante el eventual viaje de la joven a conocer la Villa, localizada a seis leguas de distancia de su hogar, el cual quedaría realmente en los alrededores de la ciudad. La villa, la urbe, misteriosa, peligrosa, lejana y llena de brillos falsos que parecen oro, pero no lo son. Ese imaginario campesino reforzaba el abismo entre el campo y la ciudad y alimentaba la idea de que dos modos de vida contrapuestos comenzaban a tomar caminos divergentes, el campesino y el citadino. Esta dicotomía ha venido a romperse en el siglo XX, particularmente en el rural próximo a las ciudades en plena expansión.

En efecto, la urbe marchó sobre las antiguas campiñas y bosques próximos, para reproducir la imagen de la propia ciudad en sus albores. En el Tomo III («Del monte a la ciudad»), de su magnífica novela Hace Tiempos (1995), Tomas Carrasquilla describe la imagen de la Medellín de comienzos de siglos:

«el cañón de este río, las cordilleras y sus aguas, las explanadas, los pueblos, las capillas de San Diego y San Esteban; tanto cortijo, tantas palmeras y sauces tantos; los bosques de mangos y naranjos, los trapiches, los molinos... La juventud actual no se figura el Medellín por aquellas calendas. Quince mil habitantes le daba la geografía... Era un pueblo amodorrado por los perfumes de los naranjos y los rosales».

Este paisaje bucólico, incluso el tamaño de la población de este paraje que era Medellín a comienzos del siglo XX, coincide con la descripción de algunos 
suburbios como los que se encuentran en Santa Elena, en el corregimiento de San Felix, en el municipio de Bello, entre otros localizados en la ruralidad próxima del Medellín del siglo XXI, pero todavía no conurbados.

Este mismo autor hacía en 1919, una semblanza de los habitantes de la Medellín de entonces:

«en las cumbres, faldas, estribaciones de estas cordilleras andinas que circunvalan la ciudad, así como el fondo de su valle, demoran, a veces dispersos, a veces inmediatos y en cantidad considerable, los lares y penates de nuestros típicos montañeses. No pierdan su carácter por más que pueblen los aledaños de un centro culto» (Carasquilla, 1995).

La imagen de una ciudad de campesinos es evidente. Esta herencia histórica tan reciente, ha alimentado en el siglo XXI un retorno, una preferencia por la vida rural entre las primeras generaciones de urbanitas, con tal fuerza que ha conseguido urbanizar los suelos rurales próximos a la ciudad metropolitana, con lo cual los campesinos metropolitanos ya no son solo labradores de la tierra, sino personas con una amplia gama de oficios urbanos y rurales tradicionales.

Si el campo ya no refleja un paisaje de actividades relacionadas con el cultivo de la tierra y la cría de ganado, sino que además combina usos y actividades típicamente urbanas, es porque la población se ha recompuesto también. Todos son campesinos, campesinos en un paisaje típico de la urbanización rural dispersa, campesinos de frontera urbano-rural, campesinos metropolitanos para quienes la imagen de ciudad no es ajena, externa, lejana y misteriosa, sino que representa un referente de identidad tan fuerte como el paisaje rural tradicional.

Este encuentro entre habitantes tradicionales y nuevos campesinos urbanos, a pesar de la herencia común, no está exento de problemas graves en todos los órdenes, desde problemas de convivencia, hasta conflictos por el uso del agua. En el paisaje rural urbanizado se recrea una confrontación entre dos modos de vida que si bien tienen hoy día elementos comunes destacados, se diferencian en temas esenciales como las relaciones sociales que en el rural tradicional mitigan diferencias de clase a través de una solidaridad orgánica que promueve lazos de familiaridad y colectividad; todo ello en abierta oposición al aislamiento que busca y promueve el urbanita campesino; en fin, los recién llegados y los históricos no acaban de encontrarse6. Todas las veredas de los municipios del área metropolitana de Medellín, tienen niveles de organización importantes ligados a la vida rural tradicional: Juntas de Acción Comunal, Juntas de Acueductos e incluso algunas mantienen organizaciones de productores, en especial en la porción norte del valle en veredas de los municipios de Barbosa y Girardota (AMVA-UN, 2011).

6 De hecho, la inspección de policía corregimental de Santa Elena, atiende, según información obtenida en entrevista personal, querellas por linderos, aguas, olores; entre otras. Muchas de estas querellas ocurren entre vecinos recién llegados y tradicionales. 
La música popular recrea la contraposición secular de los modos de vida urbano y rural. Tanto el folklore rural, el género de la música popular campesina local (música guasca), la ranchera mexicana, el son cubano, como los géneros urbanos de música popular como la salsa, la música folklórica argentina, entre otros muchos ritmos y géneros, le cantan a la vida rural, a la nostalgia por partida, a las diferencias entre campesinos y corbatas (urbanitas). En últimas, reúnen la memoria de un continente que se urbanizó a punta de ciudades de campesinos. A continuación, a modo de ilustración se incluyen algunas obras musicales que dan una idea de esta diversidad.

El Jibaro Listo de El Gran Combo de Puerto Rico. Esta canción evoca el campesino que ya se ha adaptado a la vida urbana y no va a regresar al campo, ni a la fuerza. Relata su vida pasada en el campo, regala sus posesiones y cuenta su progreso en la ciudad.

http://www.youtube.com/watch?v=RVc54reQM1w7

También de El Gran Combo, La Loma del Tamarindo le canta a la nostalgia por el paisaje rural en la infancia ya lejana. Por ejemplo:

«Recuerdo que en mi niñez, con mi viejo trabajaba, y él a la vez me enseñaba, cuanto valía la honradez... Eibamos de cuando en vez, a casa de Gumercindo, y él me decía "yo colindo con la finca del tío Pedro", me sirve de punto un cedro - y la loma del tamarindo».

http://www.youtube.com/watch?v=e3wN0TWXWjl

El Conjunto Clásico reporta un tema excepcional que habla de la nostalgia de una familia campesina que deja su casa, su tierra, su vida en el campo para marcharse llorando a «otros lugares». Este es el tema de la canción Los Rodríguez.

http://www.youtube.com/watch?v=yy7bpQpHuNM

Cambiando de género, se puede mencionar la canción del Lamento Borincano, un son cubano (en su versión original), interpretado en su una versión moderna por Marc Anthony. Esta obra cuenta la decepción del campesino que lleva sus productos a la ciudad. El campesino «va loco de contento con su cargamento par la ciudad».

http://www.youtube.com/watch?v=3xarctVa26s\&feature $=$ related

La música popular encuentra en intérpretes como Olimpo Cárdenas un tema a destacar que habla de la nostalgia por el pueblo en medio de la prosperidad que ha alcanzado en la ciudad. La canción El Provinciano dice:

7 Para seguir los enlace en la versión electrónica, presionar ctrl. + clic; o bien seleccionar el enlace y abrir el hipervínculo. En la versión impresa con el título de la canción se llega al enlace fácilmente, a través de cualquier motor de búsqueda. El autor utilizó Google. Las obras citadas están disponibles en sitios web. Se ha omitido la reproducción de partes del texto de la letra, por atender al criterio de que la música, la melodía y la instrumentación son parte esencial del trabajo artístico. 
«Las locas ilusiones me sacaron de mi pueblo. Abandone mi casa para ver la capital... En medio de esta dicha me atormenta la nostalgia Del pueblo en que dejé mi corazón».

http://www.youtube.com/watch?v=6QVt5HTsKuo.

La Canción para Carito de Mercedes Sosa es otro icono musical que relata, en lo que podría ser una metáfora poética excepcional, la nostalgia de un ave que vive en la ciudad añorando sus campos: «porque cambiaste un mar de gente, por donde gobierna la flor»».

http://www.youtube.com/watch?v=yKZgVcqpsWA

La música parrandera o guasca, una expresión local (antioqueña) del folklore campesino, es rica en obras musicales que revelan el «enfrentamiento» cultural entre las gentes del campo y los de corbata, los citadinos, como por ejemplo El negro Picante de José A Bedoya.

http://www.youtube.com/watch?v=sBj7z8Yc1sA

Aunque menos extensa al parecer, también existe una narrativa inversa, es decir, la que da cuenta de la visión urbana-rural. Un icono en este sentido lo aporta La Sonora Ponceña con su tema El pio pío:

«manejando mi carro por la carretera, yo me fui para el campo a vacacionar, con el fin de alejarme de tanto alboroto, del ambiente bullicioso de la ciudad».

Lo bello del campo termina cuando «la gallina comienza con su cacarear, los pollitos comienzan con su pio, pio; y se arma tanto lio que uno se tiene que levantar».

http://www.youtube.com/watch?v=AJqI8KvV5aA\&feature= related

Los imaginarios urbanos de ruralidad se recrean en estas obras, reafirmando las funciones que la planificación urbana tradicional le han asignado a los espacios urbanos periféricos, esencialmente producir alimentos, mantener áreas y procesos naturales, alojar a la población tradicional con sus costumbres y valores culturales: en fin, la asimilación entre los conceptos rural y natural, tan propia de la planificación urbana durante todo el siglo XX. La última obra musical insiste sobre una función nueva, la recreación al aire libre, en especial aquella que conlleva valores asociados a la naturaleza en su sentido más tradicional. Los rasgos locales de lo que denominó Berry (1976) en su momento, como un proceso de contraurbanización.

En conjunto hay una extensa narrativa musical de la transición rural urbana en América Latina, que no termina, como tampoco se agotan las expresiones culturales relacionadas. La propia Feria de Las Flores, la principal celebración urbana de la ciudad de Medellín, es una celebración de origen eminentemente rural. Los campesinos cultivadores de flores, se toman la ciudad y recrean el ancestro campesino con sus atavíos. 


\section{CONCLUSIÓN}

Es así, entre la tradición rural y el brillo urbano, que se escribe la historia de la transformación más reciente del ethos, del paisaje y de la economía campesina metropolitana. Una particular expresión del «borde urbano». Diferenciar este ámbito sociogeográfico tan particular es esencial de cara a comprender mejor su presente, para orientar su futuro lejos de visiones bucólicas de un campesino ya que no existe y del otro extremo que pretende borrar, con el argumento de la modernización inexorable y de la urbanización incontestable, una rica tradición cultural y el más variado patrimonio paisajístico, que aún se conserva en la ruralidad metropolitana, pese al vigor de su transformación.

\section{Referencias citadas}

AGUDELO, L. C., 2002 - Caracterización de los procesos de expansión de la urbanización en el valle de Aburrá; Medellín: Universidad Nacional de Colombia, sede Medellín, Facultad de Arquitectura. Escuela de Planeación Urbano-Regional. Informe de Silla de Investigación.

AGUILERA, M., BORDERÍAS URIBEONDO, M. P., GONZÁLEZ YANCI M. P., SANTOS PRECIADO, J. M., 1991 - Geografía Humana II, 516 pp.; Madrid: Universidad Nacional de Educación a Distancia. Geografía e Historia. Unidades Didácticas.

ÁREA METROPOLITANA DEL VALLE DE ABURRÁ-UNIVERSIDAD NACIONAL DE COLOMBIA, 2011 - Directrices Metropolitanas para el Ordenamiento Territorial Rural, 608 pp.; Medellín: Universidad Nacional de Colombia. Instituto de Estudios Ambientales.

ARIAS, J., 2006 - Reflexión Crítica de La Nueva Ruralidad en América Latina. ALASRU. Revista de la Asociación Latinoamericana de Sociología Rural. El Debate Teórico Rural Contemporáneo, n. ${ }^{\mathbf{0}}$ 3: 139-168. Octubre de 2006.

BAIGORRI, A., 1995 - La Sociología Rural en un contexto de incertidumbre In: V Congreso Español de Sociología - Granada. Grupo 5. Sociología Rural. Sección 1.

BERRY, B.J.L. 1976 - The counterurbanization process: Urban America since 1970. In: Urbanization and Counterurbanization (B.J.L Berry, ed.): 17-30; Beverly Hills, CA: Sage.

BOTERO. C., 1997 - El Oropel. Aventuras de dos montañeses en la capital. In: Ediciones de Autores Antioqueños: 178-193; Antioquia: Departamento de Antioquia. Secretaría de Educación y Cultura de Antioquia. Segunda Edición.

CARRASQUILLA, T., 1995 - Hace Tiempos. Tomo III: Del monte a la ciudad, 226 pp.; Medellín: Editorial Universidad Pontificia Bolivariana.

CHAYANOV. A., 1985 - La Organización de la Unidad Económica Campesina, 342 pp.; Buenos Aires: Ediciones Nueva Visión.

DEPARTAMENTO ADMINISTRATIVO NACIONAL DE ESTADÍSTICA, DANE - Censo General 2005. In: www.dane.gov.co. Consultada en Julio de 2011. 
ESTÉBANEZ, J., 1988 - Los Espacios Urbanos. In: Geografía Humana (R. Puyol, J. Estébanez, R. Méndez, eds.): 357-585; Madrid: Ed. Cátedra.

MONCLÚS, F., 1998 - La Ciudad Dispersa. Suburbanización y Nuevas Periferias. Urbanismo, Ciudad, Historia, (1): 5-16; Barcelona.

REAL ACADEMIA ESPAÑOLA, 2011 - Diccionario. Significado de la palabra Campesino. En: www.rae.es Enero de 2011.

ROBERTS, B., 1980 - Ciudades de Campesinos, 303 pp.; México: Editorial Siglo XXI.

SKERRITT, D., 1998 - Campesinos: ¿De qué hablamos? In: Cuadernos de Trabajo, 34 pp.; Xalapa, Veracruz, México: Universidad Veracruzana, Instituto de Investigaciones Histórico-Sociales.

URIBE A. M., 1885 - Geografía general y Compendio Histórico del Estado de Antioquia en Colombia, 783 pp.; Paría: Imprenta de Victor Goupy y Jourdan. Reeditado en 2006. Gobernación de Antioquia: Imprenta Departamental. 